\title{
LEAN DESIGN PROCESS FOR FORMWORK ENGINEERING
}

\author{
Chien-Ho Ko ${ }^{1}$ and Jiun-De Kuo ${ }^{2}$
}

\begin{abstract}
Formwork engineering is one of major cost factors in reinforced concrete construction, which is not only critical for the successful completion of construction projects, but also critical for profitability. Traditional formwork design process includes waste, resulting non-value-adding manpower and operational time. The purpose of this research is to utilize lean thinking in formwork design so as to enhance design correctness and eliminate waste. A lean design process for formwork enginering is established to achieve this goal. In the design process, design correctness is established to review and correct design errors. An organizational learning environment is thus built. The proposed lean design process is conceptualized using stock-flow diagrams. This research validates the applicability of the proposed approach using a real case. Application results show that the proposed method can reduce wasteful manpower and operational time in formwork engineering.
\end{abstract}

\section{KEYWORDS}

Formwork design, pull, design correctness, system dynamics.

\section{INTRODUCTION}

According to Peng (1991), in Taiwan, the reinforced concrete houses account for $87 \%$ total floor area of all houses. In addition, formwork material and labor costs occupy approximately $15 \%$ total costs of ordinary buildings and one-third of the total cost of reinforced concrete (RC) structures (Peng 1992). Thus, formwork engineering is one key construction affecting the success of a project (Santilli et al. 2011).

The design quality of formwork engineering affects construction quality. In Taiwan, $40 \%$ change order in the construction phase could be attributable to design problems (Chang et al. 2007); in other countries and areas, 26\% project deficiencies are related to poor designs (Josephson and Hammarlund 1999); and 50\% house defects are due to design flaws (NEDO 1988). Therefore, formwork engineering may affect the progress of the whole project (Ko et al. 2011).

1 Professor, Department of Civil Engineering, National Pingtung University of Science and Technology, Pingtung 91201, Taiwan, +8868 770-3202, fpecount@ yahoo.com.tw; President, Lean Construction Institute-Taiwan; Research Director, Lean Construction Institute-Asia.

2 MS, Department of Civil Engineering, National Pingtung University of Science and Technology, Pingtung 91201, Taiwan. 
Traditional formwork design is solely completed by the general contractor. Waste can be found in the design process. The formwork design, however, relates to diverse professional fields of subcontractors (e.g. formwork assembly, scaffold, rebar, electromechanical equipment, concrete work, etc.), as a result, is difficult to be planned by the general contractor without mistakes (Rosowsky et al. 1997; Chen and Shirole 2006). Poor constructability caused by poor coordination, or design change occurring in the construction phase, extends the construction period and increase the cost (Lee et al. 2009).

Although previous studies have deeply discussed mechanics, economy, and minimum usage of formwork engineering, a complete formwork design that relies on a series of design activities has not been fully discovered yet. Previous research lacks a managerial process to integrate individual procedures.

To eliminate waste in formwork engineering, a formwork design process is developed. This paper first introduces background information of the study. Formwork design requirements and system dynamics are explained, followed by the explanation of current formwork design practice. Then, the development of a lean design process for formwork engineering is discussed. To validate applicability of the developed method, a real project is analyzed. Conclusions and future research direction are finally documented.

\section{BACKGROUND INFORMATION}

\section{FORMWORK DESIGN CONCEPT}

To ensure the formwork quality and reduce construction accidents, codes for formwork design were formulated (TCCP 2000; WHSQ 2006). For example, the "Standard for Construction of Safety and Health Facilities" formulated by the Labor, Safety and Health Committee, Executive Yuan of Taiwan, of which the articles 131 and 146 stated in the 9th chapter indicate that formwork support and disassembly shall have the design made by a dedicated person. Formwork shall be constructed based on the shop drawing. Concrete shall be poured according to the plan. Operations shall be carried out according to the shop drawing. In addition, loading upon the mold shall not exceed the permitted specification before and after removing formwork support. The load borne by the newly poured floor shall also be fully considered (ILOSH 2019). Based on above guidelines, formwork operation shall be designed as a whole; the type of mold shall be selected according to the site conditions; and the formwork type, support type, soil state, fixing method, and conjunction method shall be comprehensively considered to avoid collapse and deformation.

\section{SYSTEM DYNAMICS}

This study uses System Dynamics (SD) to understand the behaviour of the propsed design method. SD, created by Professor Jay W. Forrester of the Massachusetts Institute of Technology (MIT), is an approach used to understand behavior of complex systems (Forrester 1961). SD stresses on the consideration of the entire system, understands constitutions within the system and the interaction of constitutions through a systematic thinking. SD can be used to display how the structure, policy, and delay of the system affect its development and stability with the aid of computer simulation (De Marco et al. 2012). 
It focuses on neither forecast nor single development of trend, but think over causes behind complex changes, i.e. the fundamental mechanism of the entire dynamic operation (Senge 1994). In recent years, SD applications can be found in diverse fields, such as building industry, development poly of water resource, development of automobile industry, cash flow analysis, global warming, and water supply system (Alvanchi et al. 2011; Pastorino et al. 2011; Hassanzadeh et al. 2012).

System Dynamics model mainly consists of four basic elements, i.e. stocks, flows, arrows, and auxiliary variables. These elements are explained using Vensim notations as follows (Eberlein and Peterson 1992):

\section{Stocks}

Stocks refer to the status of a system variable at a specific time. Stock values are the result produced by accumulating the net balance of inflows and outflows. In other words, they are the accumulation result in the system in the past.

\section{Flows}

Also known as rates, Flows indicate the change in a stock variable and represent the behavior at a moment. Their values are mostly decided by the interaction between stock variables and auxiliary variables, and hence can be viewed as the control variables of the system. Flows are directional, so flows are called "Inflow" when they flow into a stock. In the contrary, "outflows" flow out of a stock.

\section{Auxiliary Variables}

Auxiliary variables, also known as converters, indicate an input value, or directly convert an input into an output.

\section{Arrows}

Arrows, also called connectors, represent the transmission of relevant information between stocks, flows, and auxiliary variables.

Stocks and flows are used for deducing system status, i.e. presentation of element flows. Arrows and auxiliary variables can be used for deducing causal feedback loop, i.e. representation of variable information flow. Using population as an example, in Figure 1, population is stocks, births and deaths are flows, of which births are inflows and deaths are outflows. Birth rate and death rate are auxiliary variables. With the aid of System Dynamics, the dynamic relation between birth rate, population, and death rate can be analyzed.

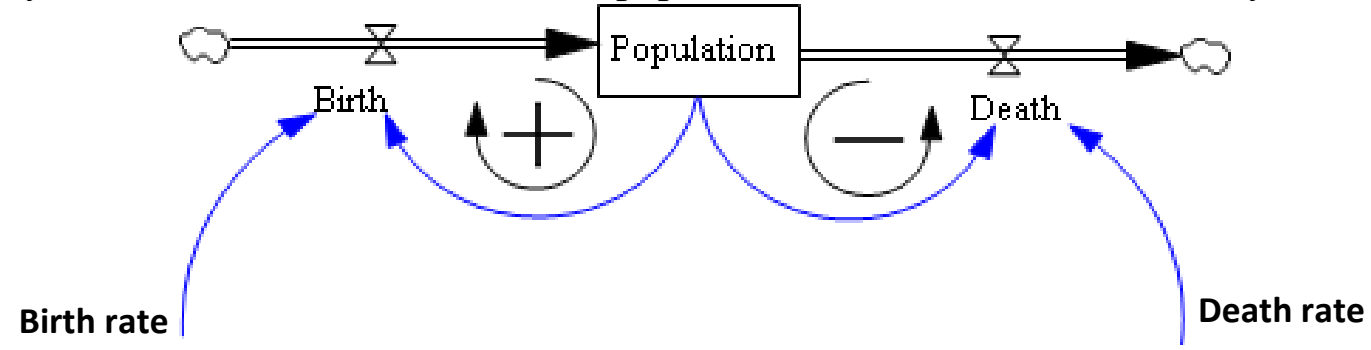

Figure 1: Population Stock-Flow Diagram 


\section{CURRENT-STATE VALUE STREAM MAPPING}

Current formwork design is composed of preliminary design and detailed design processes, which are usually finished by the general contractor (GC). In preliminary design phase, the site manager draws the building system model according to the design drawing supplied by the architect. In the detailed design phase, the structural engineer establishes the detailed structure according to the preliminary formwork model. While assembling the molds, site manager is responsible for coordinating with the subcontractors such as rebar, formwork, water and electricity about the assembly schedule. If design errors are found or molds cannot be assembled as designed, GC (i.e. site manager and structural engineer) is responsible for changing the design. The formwork subcontractor shall revise the corresponding assembly plan and shop drawing in accordance with the revised design. The scenario is represented using the current-state value stream map demonstrated in Figure 2. According to the figure, problems for the current practice are explained as follows:

1. Before the site manager delivers formwork design for mechanical analysis, the structural engineers do not have an opportunity to express their comments on the design. The chance to obtain a better design is missing.

2. The formwork assembly plan is made by the formwork subcontractor. However, mold assembly may involve other subcontractor activities (e.g. scaffold, rebar, wires, and pipes). A perfect plan is difficult to be conducted by solely formwork subcontractor. As a result, poor constructability and design errors may influence construction delivery and therefore increases cost and deteriorate quality.

3. Current formwork design drawings are mostly the 2D graphs. However, formwork, wiring, piping, and rebar operations overlap. It is hard to find out the conflictions by the 2D graph, and thus the possibility of change order increases.

\section{FUTURE-STATE VALUE STREAM MAPPING}

\section{Pull Design}

This research adopts the Last Planner and Work Structuring raised by Ballard (2000) to pull the design process so as to make the design flow stable. In traditional formwork design process, the formwork planning is carried out immediately after the general contractor determines the project target. Working items are confirmed before making the assembly schedule. The scheduled working items are completed based on the available resources. Uncompleted works are awaited and can only be finished when resources are sufficient. Traditional planning system, however, often cannot complete the formwork design according to the predetermined design schedule. In order that the scheduled items can be carried out successfully, the Last Planner is added to the formwork design to control the design progress. When making the formwork design schedule, the Last Planner evaluates the current design status, and "pull" the qualified work items (i.e. ready for work) into the design schedule. If the scheduled design items fail to be conducted because of the insufficient preconditions, other operations (backlog) or the future items can be implemented in advance in order to maintain the smooth design progress. This method can 
avoid rushing through the job caused by the postponement of the work items. When executing the design plan, the resources necessary for the work items, which should be carried out in the future, should be prepared ahead. In case that work items cannot be finished within the specified time, root causes should be discussed.
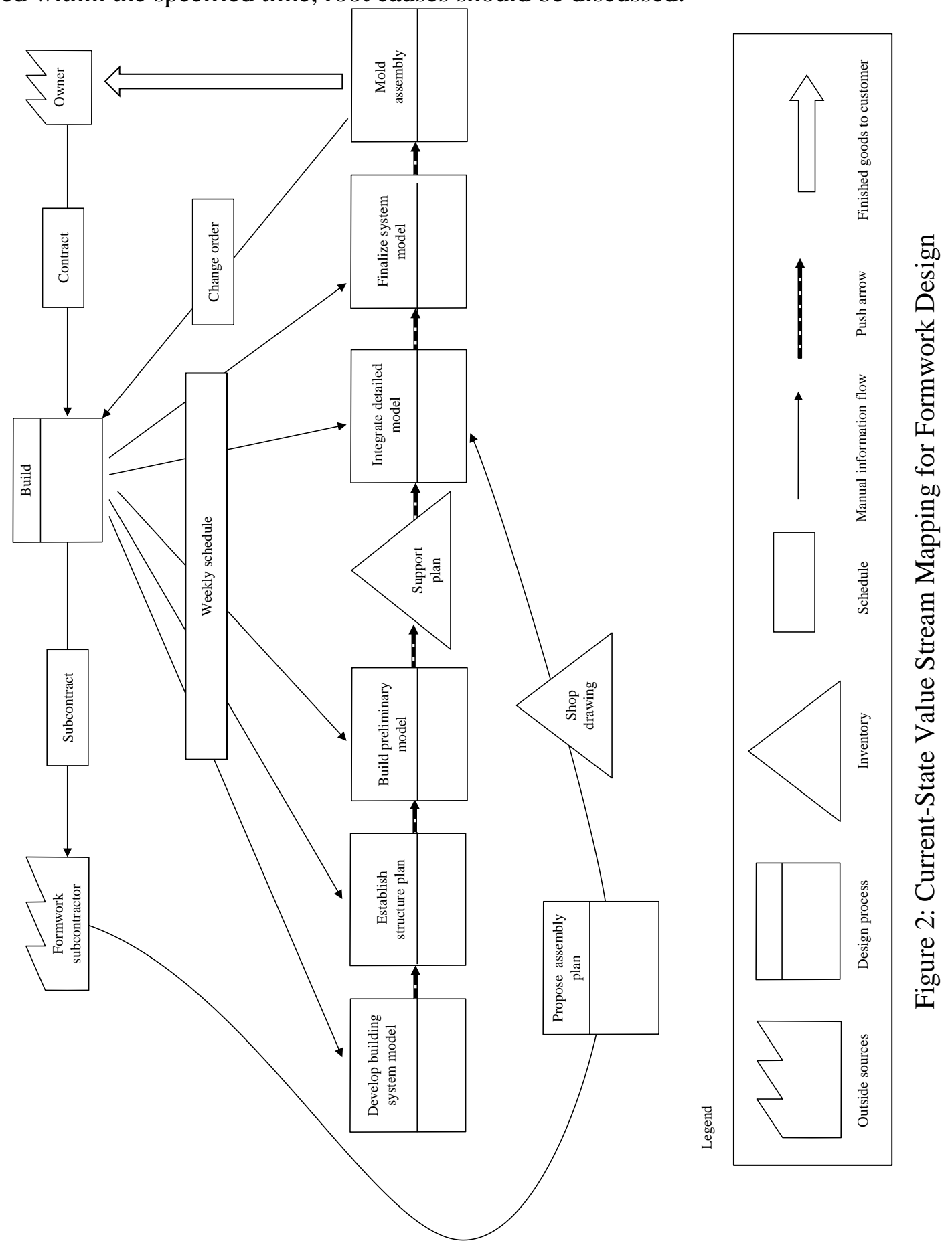


\section{Pursuing Perfection}

To design the formwork system meeting owner requirements, pull manufacturing and the concurrent design are used for pulling the work items within the system. Designers and owners are take part in design together. The improved process is drawn into the futurestate map.

Since formwork design and planning differs from manufacturing process, i.e. the processed work pieces cannot be sent to the next work station through the belt, the supermarket pull system is used for pull the upstream supplier and downstream customer. Production card is a signal to start production, and withdrawal card is a purchase order for receiving items. The mark of the supermarket is left-opened, which corresponds to the supplier. When the preliminary design correctness is reviewed, incomplete and unclear items must be returned to the responsible designer for modification. The withdrawal card also can be used for pulling design to enable the upstream supplier to make a thoroughly improvement in the information sent from the downstream. Finally, the general contractor integrates the formwork detailed model to pull the preliminary design correctness to complete the formwork design.

The value of the completed formwork system model is to satisfy general contractor's requirements. Design mistakes and conflictions can be reduced through the improvement of design correctness, so as to improve the design reliability. The general contractor uses the electronic information flow transfers BIM, and uses the formwork system model to pull the detailed design correctness. As a result, design operations can be pulled in this phase.

The future-state map of the lean design process for formwork enginering is integrated and displayed in Figure 3. Owner contracts the project with the general contractor. General contractor outsources the formwork engineering to the formwork subcontractor. The formwork subcontractor then designs the formwork plan, entrusts the structural engineers to analyze the formwork mechanical behavior. The lean design process for formwork enginering is raised for allowing the general contractor, formwork subcontractor, structural engineers, Architectural/Engineering, and related third parties to jointly participate in the design. With the aid of the feedbacks and modifications in each design phase, the occurrence of design error and the risk of change order during construction phase can be reduced. Furthermore, the pull process is introduced into the design progress so that the design process is smoothed.

\section{VERIFICATION}

In order to validate applicability of the proposed method, a real case is used. The studied case, located in Taiwan, is a building project with one basement and four stories. The total floor area is 2185 square meters. In order to analyze the waste made by poor design, formwork operations are analyzed. In this study, formwork assembly and processing are divided into nine operations, i.e. "measure," "walk," "find," "pull," "cut," "pass," "wait," nail," and "mend." The value-adding activities in formwork assembly and processing include "measure," "pull," "cut," "pass," "nail," and "mend." The proportion of valueadding activities accounts for $56.8 \%$ operational time. By multiplying design weights, the design weight of formwork assembly and processing can be obtained. These weights 
represent the proportion of design category results in formwork assembly and processing activity. This case study designs the formwork system using traditional method that has no design correctness examination and organizational learning mechanism. However, in building projects, the rework cost due to design error is up to $35 \%$ (Hammarlund and Josephson 1991; Choo 2008). The use of the lean design process suggested in this paper can eliminate unnecessary waste in formwork assemble and processing.

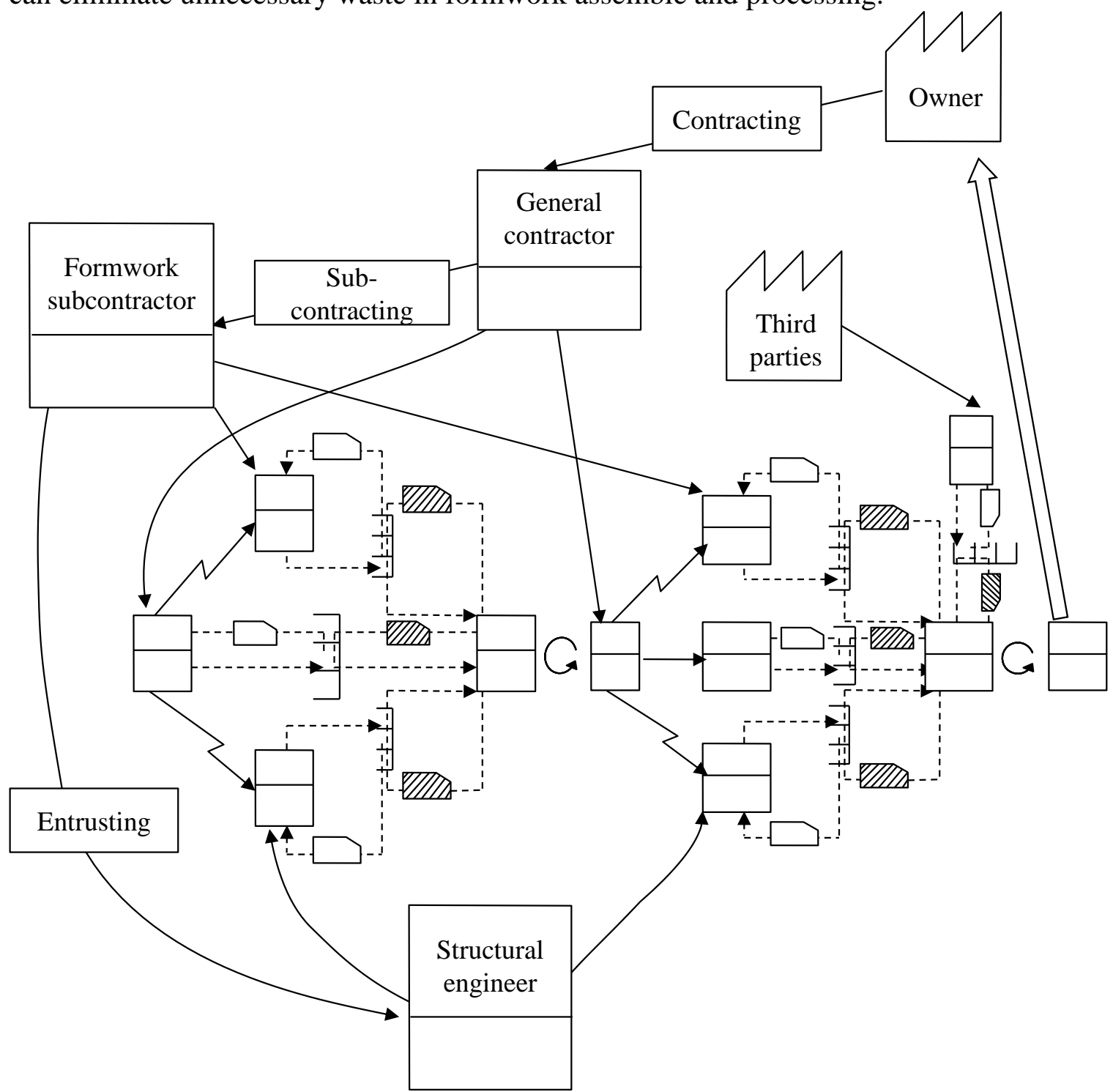

Figure 3: Future-State Map of Lean Design Process for Formwork Enginering

\section{CONCLUSIONS}

To reduce waste caused in formwork design, formwork turnkey contract is used to enhance the collaboration between formwork design and assembly members. Furthermore, to establish the organizational learning environment, design correctness ratio is developed to gradually improve design correctness and constructability through co-review and 
modification. Finally, feasibility of the lean design process for formwork enginering is validated using a real building project using System Dynamics.

In the current practice, formwork design and assembly are carried out respectively by the general contractor and formwork subcontractor. This practice makes formwork design become a mere formality. In this research, the design correctness and constructability are considered while designing the formwork. In addition, through the concurrent design, the design team members can jointly collaborate to help stakeholders identify problems as early as possible and therefore enhance design correctness. The proposed lean design process feedbacks problems to the responsible designer through evaluating design correctness. The design and construction teams are invited to jointly participate in design phase making design drawings more complete and accurate.

\section{REFERENCES}

Alvanchi, A., Lee, S., and AbouRizk, S. (2011). "Modeling Framework and Architecture of Hybrid System Dynamics and Discrete Event Simulation for Construction." Computer-Aided Civil and Infrastructure Engineering, 26(2), 77-91.

Ballard, G. (2000). The Last Planner System of Production Control. PhD Thesis, University of Birmingham, UK.

Chang, S.D., Shi, G S., and Chou, Y.S. (2007). Courses for Change Order and Remedy Methods in the Construction Phase. Grant number 96642, China Engineering Consultants, Inc. (in Chinese).

Chen, S.S., and Shirole, A.M. (2006). "Integration of Information and Automation Technologies in Bridge Engineering and Management: Extending the State of the Art." Journal of the Transportation Research Board, 1976, 3-12.

Choo, Y. S. (2008). Reasons and Cost for Design Change during Construction and Correspondence Process Analysis. MS Thesis, National Cheng Kung University, Tainan, Taiwan.

De Marco, A., Cagliano, A.C., Nervo, M.L., and Rafele, C. (2012). "Using System Dynamics to Assess the Impact of RFID Technology on Retail Operations." International Journal of Production Economics, 135(1), 333-344.

Eberlein, R. and Peterson, D. (1992). "Understanding Models with Vensim." European Journal of Operational Research, 59(1), 216-219.

Forrester, J. W. (1961). Industrial Dynamics. Pegasus Communications, NY.

Hammarlund, Y. and Josephson, P.E. (1991). "Sources of Quality Failures in Building." Proceedings of the European Symposium on Management, Quality and Economics in Housing and Other Building Sectors, 671-679.

Hassanzadeh, E., Zarghami, M., and Hassanzadeh, Y. (2012). "Determining the Main Factors in Declining the Urmia Lake Level by Using System Dynamics Modeling." Water Resources Management, 26(1), 129-145.

Institute of Labor, Occupational Safety and Health (ILOSH). (2019). Construction Health and Facilities Hygiene Standard, http://www.ilosh.gov.tw/Law/LawPublish.aspx?LID=19, Retrieved on February 16, 2019. 
Josephson, P.E. and Hammarlund, Y. (1999). "The Causes and Costs of Defects in Construction: A Study of Seven Building Projects.” Automation in Construction, 8(6), 681-687.

Ko, C.H. and Kuo, J.D. (2019). “Making Formwork Design Lean.” Journal of Engineering, Project, and Production Management, 9(1), 29-47.

Ko, C.H., Wang, W.C., and Kuo, J.D. (2011). "Improving Formwork Engineering Using the Toyota Way." Journal of Engineering, Project, and Production Management, 1(1), 13-27.

Lee, M.J., Ryoo, B.Y., Sullivan, K.T., and Hanna, A.S. (2009). "RETRACTED: Development of automated change order impact detection and quantification system." Automation in Construction, 18(5), 525-535.

National Economic Development Office (NEDO). (1998). Faster building for commerce, HMSO, London.

Pastorino, R., Naya, M. A., Pérez, J. A., and Cuadrado, J. (2011). "Geared PM Coreless Motor Modelling for Driver's Force Feedback in Steer-By-Wire Systems." Mechatronics, 21(6), 1043-1054.

Peng, Y.H. (1991). Investigation and Analysis of Taiwan Construction Energy, Research Report, Architecture and Building Research Institute, Ministry of the Interior, Taipei, Taiwan (in Chinese).

Peng, Y.H. (1992). Investigation and Analysis of Taiwan Construction Energy II, Research Report, Architecture and Building Research Institute, Ministry of the Interior, Taipei, Taiwan (in Chinese).

Rosowsky, D.V., Philbrick, T.W., and Huston, D.R. (1997). "Observations from Shore Load Measurements during Concrete Construction." Journal of Performance of Constructed Facilities, 11(1), 18-24.

Santilli, A., Puente, I., and Tanco, M.A. (2011). "Factorial Design Study to Determine the Significant Parameters of Fresh Concrete Lateral Pressure and Initial Rate of Pressure Decay." Construction and Building Materials, 25(4), 1946-1955.

Senge, P.M. (1990). The Fifth Discipline- The Art and practice of the Learning Organization, Bantam Dell Pub Group.

Technical Committee on Construction Practice (TCCP). (2000). Code of Practice for Formwork, SPRING Singapore, Singapore.

Workplace Health and Safety Queensland (WHSQ). (2006). Formwork Code of Practice. Department of Justice and Attorney-General, Queensland Government, 2006. 
Ko, C.H. and Kuo, J.D 